\title{
A DANÇA ENQUANTO CONHECIMENTO NOS CURSOS DE FORMAÇÃO INICIAL EM EDUCAÇÃO FÍSICA
}

\section{DANCE AS KNOWLEDGE IN INITIAL TRAINING COURSES IN PHYSICAL EDUCATION}

\author{
ORTIGARA, Vidalcir \\ Universidade do Extremo Sul Catarinense (UNESC) \\ vdo@unesc.net \\ BONA, Bruna Carolini De \\ Universidade do Extremo Sul Catarinense (UNESC) \\ brunacarolinidebona@hotmail.com \\ CARDOSO, Ana Lúcia \\ Universidade do Extremo Sul Catarinense (UNESC) \\ anc@unesc.net \\ EUZÉBIO, Carlos Augusto \\ Universidade do Extremo Sul Catarinense (UNESC) \\ cae@unes.net
}

\begin{abstract}
RESUMO O objetivo deste artigo é compreender as relações entre as políticas públicas para a educação e o ensino de dança na formação inicial de professores de Educação Física. A partir da análise das referências básicas utilizadas em disciplinas que têm a dança como conteúdo, buscamos levantar elementos de convergência e divergência entre tais referências e as orientações dessas políticas públicas educacionais. Das 24 obras analisadas, 15 são convergentes com as políticas, 3 divergentes e 6 sem posicionamento explícito. Isso permitiu a análise em relação à provável orientação das disciplinas de ensino da dança.
\end{abstract}

Palavras-chave: Políticas públicas. Formação de professores. Formação inicial de professores. Educação Física. Ensino da Dança.

ABSTRACT The Goal is to understand the relationship between public policies for education and teaching dance in the initial training of Physical Education teachers. From the analysis of the basic references used in dance disciplines that have the content, we seek to identify elements of convergence and divergence between these references and educational guidelines for these policies. Of the 24 articles analyzed, 15 are convergent with the policies, 3 and 6 divergent without explicit placement. This allowed analysis approvable orientation of the disciplines of dance education relationship.

Keyword: Public Policy-training of teachers. Initial Training of Physical Education Teachers. Teaching Dance. 


\section{INTRODUÇÃO}

Os anos de 1990 testemunharam um período de grande turbulência na economia mundial. Procurando solucionar a crise, organismos internacionais iniciam a elaboração de reformas nas mais diversas práticas sociais buscando amenizar os efeitos de tão vertiginosa mudança. Na educação, os critérios utilizados nas reformas ainda estão presentes nas políticas educacionais, influenciando na elaboração dos currículos, na organização escolar, nas políticas de formação e em outras áreas.

Estudos de Moraes (2003, 2009), Moraes e Torriglia (2003) e Evangelista e Shiroma (2003) apontam a educação pretendida a partir dessas reformas. Uma educação que ganha importância por desenvolver as competências para garantir a sobrevivência no núcleo de um mercado fragmentado e com elevados níveis de exclusão. Uma educação que recebe como tarefa a formação para a empregabilidade, transformando o aluno em um ser proativo, trabalhador e tolerante na hora do desemprego e o professor em um espelho de profissional exemplar dentro da escola.

As políticas desenvolvidas nesse período tomam por base os saberes instrumentais relacionados ao usar, ao fazer $e$ ao interagir. Exaltam o desenvolvimento das competências e deixam de lado uma importante ferramenta para a formação humana: o conhecimento. David (2002) nos mostra que a competência passa a ter um sentido ampliado, assumindo a função de formação educativa e qualificação para o trabalho e a Educação Física, em meio a essas políticas, enfrenta problemas que vão desde sua concepção de formação profissional até a própria operacionalização dos conteúdos.

As reformas ocorreram. Novas políticas públicas educacionais foram elaboradas e aprovadas no Brasil. Cerca de vinte anos após o período de reformas, cabe a reflexão e a avaliação da implementação de tais políticas no país, destacando a Resolução CNE/CP 1, do Conselho Nacional de Educação, de 18 de fevereiro de 2002 (Brasil, 2002a), a Resolução CNE/CP 2 de 19 de fevereiro de 2002 (Brasil, 2002b), e as Diretrizes Curriculares Nacionais para os Cursos de Graduação em Educação Física - Resolução CNE/CES n7/2004 (Brasil, 2004), discutidas por autores referenciados neste trabalho. 
Atos de Pesquisa em Educação - ISSN 1809-0354

Blumenau - vol. 11, n. 2, p.572-589 ago./nov. 2016

DOI: http://dx.doi.org/10.7867/1809-0354.2016v11n2p572-589

Tendo por base o trabalho de Euzébio e Ortigara (2011), o qual procurou explicitar que conhecimento esporte vem sendo tratado nos cursos de formação inicial de professores de Educação Física, buscamos compreender de que forma 0 conhecimento dança é abordado nos cursos de formação inicial em Educação Física na região sul catarinense e a possível relação com as políticas educacionais brasileiras para a formação docente. Para a análise da abordagem do conhecimento dança realizamos levantamento, junto às matrizes curriculares dos cursos, das disciplinas que abordam a dança. Nos cinco $\operatorname{cursos}^{1}$ da região encontramos sete disciplinas que abordam esse conteúdo. Tomamos como elemento de análise a bibliografia básica advindas das informações solicitadas junto à coordenação de cada curso, via e-mail. Nas sete disciplinas estão referenciadas 24 obras. A partir deste material teremos condições de verificar a aproximação ou o afastamento dos cursos de formação docente em relação às políticas públicas educacionais, suas intenções e objetivos em relação à formação dos futuros professores de Educação Física de nossa região.

\section{POLÍtICAS PÚBLICAS E NEOLIBERALISMO: A EDUCAÇÃo EM MEIO ÀS MUDANÇAS}

Inicialmente nos cabe uma melhor compreensão do processo de mudanças ocorrido nas políticas públicas brasileiras sob a égide de uma organização neoliberal. As mudanças não ocorreram sem propósito. Seguindo as orientações de organismos internacionais, a educação brasileira inicia seu período de reformas vislumbrando um novo projeto educacional, um projeto desenvolvido para atender e solucionar os problemas do mercado capitalista de força de trabalho. A necessidade da reforma justifica-se por afirmarem que a educação era uma barreira para o desenvolvimento socioeconômico do país, ressaltando a importância de mudanças no sistema educacional decorrentes do aumento do nível da competitividade no mercado e da busca de conhecimentos e informações necessárias para a ocupação dos postos de trabalho. O documento Educación y conocimiento: eje de La tranformación produtiva

\footnotetext{
${ }^{1}$ Os nomes das instituições são resguardados pela pesquisa, mantendo a descrição em relação às disciplinas analisadas. Ao tratar das instituições, utilizaremos a sigla IES (Instituição de Ensino Superior) somado a certo número: IES I, IES II, IES III, IES IV, IES V.
} 
Atos de Pesquisa em Educação - ISSN 1809-0354

Blumenau - vol. 11, n. 2, p.572-589 ago./nov. 2016

DOI: http://dx.doi.org/10.7867/1809-0354.2016v11n2p572-589

com equidade, da Comissão Econômica para a América latina e Caribe da Organização para a Educação, a Ciência e a Cultura das Nações Unidas CEPAL/UNESCO - apresenta-se como uma das orientações desenvolvidas nesse período, apontando a difusão do progresso técnico e a sua incorporação aos sistemas de bens de serviço como condição para tornar os países latino-americanos competitivos no mercado mundial.

\begin{abstract}
A acumulação de conhecimentos técnicos implica uma complementação entre criação de conhecimento, inovação e difusão. Para desenvolver e utilizar plenamente as novas tecnologias resultam imprescindíveis alguns processos fundamentais de aprendizagem, em particular as modalidades de aprendizagem mediante a prática [...]. (CEPAL/UNESCO, 1992, apud MORAES; TORRIGLIA, 2003, p. 46).
\end{abstract}

O projeto proposto pela CEPAL em 1992 pretendia uma transformação produtiva tendo como eixo para a mudança a educação e o conhecimento. Porém, tornam-se evidentes em seus documentos as modalidades propostas para a educação: usar, fazer e interagir. Esses critérios nortearam as elaborações das prioridades nas políticas de formação, a elaboração dos currículos, a organização escolar e a articulação entre formação docente e prática pedagógica que refletem até hoje nas políticas educacionais, restringindo fortemente possibilidades mais amplas e críticas de conhecimento.

Se a educação era reconhecida nesse projeto como eixo para o desenvolvimento produtivo, certamente o projeto de formação docente foi tomado como elemento de recomposição da hegemonia dominante.

Para além da performance educativa do sistema educacional, mais uma vez está em jogo o controle sobre a maior fração do contingente de servidores públicos, a dos professores, a quem se reserva a responsabilidade de formar as novas gerações. (EVANGELISTA; SHIROMA, 2003, p. 85)

Não se trata apenas de preparar os professores que irão qualificar os futuros trabalhadores, mas também de transmitir valores, posturas, conhecimentos, formas de ser e estar no mundo. O professor deve servir como espelho de profissional exemplar para seus alunos. É evidente a importância do mesmo como mediador entre os alunos e a demanda da contemporaneidade, surgindo assim o professorprofissional, sendo este um dos grandes desafios da reforma: conduzir os professores pelos caminhos dessa profissionalização. Outro motivo para as reformas foi adicionar 
Atos de Pesquisa em Educação - ISSN 1809-0354

Blumenau - vol. 11, n. 2, p.572-589 ago./nov. 2016

DOI: http://dx.doi.org/10.7867/1809-0354.2016v11n2p572-589

para a educação a tarefa de formar para a empregabilidade, transformando o aluno em um cidadão preparado para o mercado de trabalho.

Os documentos produzidos nas reformas educacionais do governo do presidente Fernando Henrique Cardoso (FHC) - oriundos da crise educacional delineada por Fernando Collor- imprimiram forte caráter privatista e flexível às políticas educacionais, como é o caso da LDBEN - Lei de Diretrizes e Bases da Educação Nacional (Brasil, 1996). O projeto tinha por pressuposto a existência de um sujeito incansável em sua busca de se engajar no mercado de trabalho.

\begin{abstract}
Nesse universo abstrato trafegavam professores e alunos, levados a acreditar que portar competências e habilidades seria suficiente para colocá-los em sintonia com o mercado de trabalho. Nesse quadro, a escola foi gradativamente responsabilizada pelos problemas sociais e os indivíduos culpabilizados por seu fracasso pessoal. (EVANGELISTA; SHIROMA, 2003, p. 87)
\end{abstract}

A jogada está em propor nos documentos o que não se efetiva na prática. "A política de FHC substituiu a demanda por um professor capaz do exercício crítico em sua profissão por um professor sem críticas, cuja capacidade reflexiva foi suprimida". (EVANGELISTA; SHIROMA, 2003, p.95). A Resolução CNE/CP 1, do Conselho Nacional de Educação, de 18 de fevereiro de 2002 (Brasil, 2002a), e a Resolução CNE/CP 2, de 19 de fevereiro de 2002 (Brasil, 2002b), são analisadas por Moraes e Torriglia (2003) como documentos idealistas, propositivos e prescritivos, sendo incoerentes de maneira geral e precariamente alicerçados. Destaca-se a ideia de um profissional formado para dominar um conjunto de competências ligadas ao domínio de seus conteúdos e de seus significados em diferentes contextos, à articulação dos conhecimentos de processos de investigação e ao gerenciamento do desenvolvimento profissional. Como se vê, o discurso proclama um futuro professor muito qualificado e competente, porém, como mão-de-obra não deve ultrapassar o que efetivamente the foi planejado, do que é previsto em sua formação, do alcance do conhecimento que the é permitido. Outro problema recorrente de todo esse processo é o aligeiramento da formação docente que impacta profundamente na produção de conhecimento. "Com a proliferação de cursos aligeirados que fornecem certificados em massa, o egresso nem se qualifica nem consegue emprego". (EVANGELISTA; SHIROMA, 2003, p. 94). 
Atos de Pesquisa em Educação - ISSN 1809-0354

Blumenau - vol. 11, n. 2, p.572-589 ago./nov. 2016

DOI: http://dx.doi.org/10.7867/1809-0354.2016v11n2p572-589

A falta de discussão teórica nas pesquisas educacionais, deixando-a em segundo plano, segundo Moraes (2003), repercute na produção de conhecimento da área. Este "fim da teoria" vem acompanhado de uma utopia educacional que considera a teoria uma perda de tempo ou uma especulação metafísica. "Talvez a causa mais imediata desta 'marcha a ré intelectual' e teórica esteja na definição e efetivação das próprias políticas públicas educacionais, em níveis nacional e internacional". (MORAES, 2003, p. 154).

As políticas de resultados propiciaram a desagregação do ambiente acadêmico, promovendo o individualismo e descaracterizando a função de docentes e pesquisadores. Para Moraes (2009, p.324) "é o professor profissional, informado pela epistemologia da prática, competente para responder às questões de suas tarefas cotidianas".

Analisando as Diretrizes Curriculares do Conselho Nacional de Educação, verifica-se claramente o conhecimento pretendido: um conhecimento técnicocientífico que busca direcionar a ação curricular para uma racionalidade prática e um modelo de formação baseado em competências forjadas a partir de situaçõesproblema. Procurando não transparecer a lógica das competências, as diretrizes apontam em direção a uma capacitação ampliada, ao contrário da lógica de adequação direta ao mercado e à empregabilidade. De acordo com David (2002), a competência passa a ter um sentido ampliado e assume a função de formação educativa e qualificação para o trabalho.

$\mathrm{Na}$ área específica de graduação em Educação Física, as Diretrizes Curriculares Nacionais defendem a necessidade de se construir um perfil bem delineado para a intervenção educativa e pedagógica na escola. Tal preocupação deveria ser extensiva às demais intervenções da docência na sociedade. Esta área de conhecimento aponta para um tratamento diferenciado em razão de seu desenvolvimento histórico, científico, cultural e social e por tratar-se de uma área demarcada por uma prática pedagógica de caráter interdisciplinar. Segundo David (2002, p.127),

Enquanto área de conhecimento, a educação física configura-se como um lugar onde sistematiza, acumula, reflete, reorganiza e transforma saberes junto e/ou decorrentes da cultura corporal referenciada, como núcleo epistêmico, o conhecimento do corpo em suas várias dimensões e interrelações com a ciência, a cultura e a sociedade. 
Atos de Pesquisa em Educação - ISSN 1809-0354

Blumenau - vol. 11, n. 2, p.572-589 ago./nov. 2016

DOI: http://dx.doi.org/10.7867/1809-0354.2016v11n2p572-589

A ação educativa da área caracteriza-se por procedimentos metodológicos fundados em bases culturais, científicas, estéticas, éticas e sociais do corpo, direcionados para a formação social e humana. Para David (2002, p.127), "o que muda e a distingue do processo educacional formal são, evidentemente, os procedimentos teóricos/metodológicos e as distintas pedagogias aplicadas num determinado locus social". Socialmente a Educação Física contribui para o desenvolvimento da pessoa humana no sentido da qualidade de vida pessoal e coletiva, tendo o corpo como centro da ação educativa nos mais variados aspectos. Se a formação docente tem como eixo central a formação de competências a partir de situações-problema e a pesquisa voltada a resolver estas questões, ela se isola da área de desenvolvimento acadêmico-científico e cultural dentro da universidade, materializando o "fim da teoria" apontado por Moraes (2003).

De acordo com Taffarel (2012), a divisão acadêmica nas mais diversas áreas de formação, inclusive na formação em Educação Física, leva à sua fragilidade pelo esvaziamento teórico e contribui com a desregulamentação do mundo do trabalho. Segundo a autora, a realidade atual na formação de professores permite levantar a hipótese de que está em curso um processo de desqualificação e destruição das forças produtivas. Processo que se consolida pela retirada dos intelectuais orgânicos da luta de classes e sua transformação em intelectuais institucionais inseridos na implantação das políticas públicas mundiais de educação, pelo "recuo da teoria" (MORAES, 2003), pela fragmentação das Diretrizes Curriculares, pelo rebaixamento teórico nos currículos de graduação, pela desregulamentação profissional e, no caso notório da Educação Física, pela criação de conselhos de fiscalização profissional, representados pelo Conselho Federal de Educação Física e por Conselhos Regionais de Educação Física (CONFEF/CREF).

As políticas públicas de formação de professores, baseadas numa organização neoliberal de estado, direcionam a formação das mais diversas profissões, inclusive a docência em Educação Física. Porém, nos cabe a compreensão da influência dessas orientações políticas na formação de professores de nosso país. Buscamos compreender essa relação a partir da bibliografia utilizada no trato com o conhecimento dança nos cursos superiores de licenciatura em Educação Física da região sul catarinense. 
Atos de Pesquisa em Educação - ISSN 1809-0354

Blumenau - vol. 11, n. 2, p.572-589 ago./nov. 2016

DOI: http://dx.doi.org/10.7867/1809-0354.2016v11n2p572-589

\section{POLÍTICAS PÚBLICAS E FORMAÇÃO DE PROFESSORES: UMA RELAÇÃO A SER ANALISADA}

Nas cinco instituições que possuem curso de formação docente em Educação Física da região sul catarinense, encontramos sete disciplinas que abordam o conteúdo dança. Tomamos para análise as bibliografias indicadas em seus planos de ensino como base das mesmas, isto é, consideramos que essas obras são as que os alunos obrigatoriamente deverão estudar em seu curso.

A análise das vinte e quatro obras ocorreu em forma de síntese, buscando, a partir desse estudo, traçar uma relação com as orientações das políticas públicas para a formação docente, procurando verificar as convergências e divergências em relação ao posicionamento dessas políticas frente às questões do conhecimento. Como já mencionado anteriormente, autores já apontavam, há cerca de duas décadas, o compromisso dessas políticas com a educação: formar todos para o mercado de trabalho. Segundo Gentili (1996, p.25-26), "o sistema educacional deve promover o que os neoliberais chamam de empregabilidade. Isto é, a capacidade flexível de adaptação individual às demandas do mercado de trabalho". Sobre a formação docente, Moraes (2009) aponta que a construção de um tipo de profissional de educação não está mais baseada no conhecimento que possui ou transmite, mas nas competências que constrói e habilita para o convívio nas situações mais adversas.

Com base neste referencial e após a análise das obras chegamos a três posicionamentos diferenciados: 1) obras convergentes com as orientações das políticas públicas de formação docente, de posicionamento não crítico e orientadas por um conhecimento técnico, prático e instrumental; 2) obras divergentes das orientações das políticas públicas de formação docente, de posicionamento crítico, orientadas por um conhecimento ampliado; 3 ) obras sem direcionamento quanto às políticas públicas de formação docente e com um posicionamento não explicitado. $\mathrm{A}$ seguir apresentamos a análise de cada posicionamento a partir de suas obras.

\subsection{OBRAS CONVERGENTES ÀS ORIENTAÇÕES DAS POLÍTICAS PÚBLICAS DE FORMAÇÃO DE PROFESSORES}


Atos de Pesquisa em Educação - ISSN 1809-0354

Blumenau - vol. 11, n. 2, p.572-589 ago./nov. 2016

DOI: http://dx.doi.org/10.7867/1809-0354.2016v11n2p572-589

Das vinte e quatro obras analisadas, quatorze, isto é, $62 \%$ delas, possuem concepção de conhecimento convergente às orientações das políticas públicas de formação, caracterizando a dança em sua dimensão técnica. Grande parte das obras presentes nesse posicionamento buscam apresentar propostas de utilização da dança para professores de Educação Física, coreógrafos, instrutores, entre outros profissionais de diferentes áreas. As propostas vão desde o desenvolvimento de todas as possibilidades do movimento corporal sob aspectos físicos e psíquicos do corpo, como em Brikman (1989), até o entendimento do ensino da dança enquanto essencial para o desenvolvimento de habilidades como a leitura e a escrita, conforme Ferreira (2009).

Obras como as de Ferreira (2009), Garcia e Haas (2003), Rangel (2002), Nanni (2002), Verderi (1998) e Haselbach (1988), que apresentam elementos da dança na escola, a compreendem como auxiliar na execução de tarefas e na resolução de problemas, como recurso para o aprimoramento das habilidades básicas e ferramenta para o desenvolvimento das potencialidades humanas. Além disso, a dança é apontada como auxiliar na melhoria do processo de aprendizagem do aluno e no desenvolvimento de suas habilidades, considerando-a elemento ampliador da capacidade de interação social e componente importante no desenvolvimento psicomotor, cognitivo e afetivo social.

Outras obras, como as de Ossana (1988), Prina e Padovan (2000) e Calazans (2003) se voltam especificamente ao ensino da dança profissional, tratando das escolas clássicas e modernas em seus exercícios, apresentando conceitos altamente técnicos, dissociados da dança enquanto conteúdo curricular da Educação Física escolar. Dantas (2005) apresenta uma ampla revisão dos aspectos anatômicos e cinesiológicos do corpo humano, relacionando-os às práticas de "alongamento e flexionamento" para a dança e demais atividades. O quadro se encerra com os Parâmetros Curriculares Nacionais (Brasil, 1997), que por ser um documento organizado pelo Ministério da Educação, inevitavelmente conflui para as políticas públicas brasileiras.

Analisando as políticas públicas de formação de professores pela lógica das competências, as obras referidas anteriormente reforçam esse modelo de formação. A dança, na perspectiva dessas obras, contribui para a formação baseada na 
Atos de Pesquisa em Educação - ISSN 1809-0354

Blumenau - vol. 11, n. 2, p.572-589 ago./nov. 2016

DOI: http://dx.doi.org/10.7867/1809-0354.2016v11n2p572-589

empregabilidade a partir do momento que se transforma em ferramenta auxiliar no desenvolvimento da boa conduta, da disciplina, da concentração e memória, da autonomia e responsabilidade. Quando o interesse se volta a desenvolver um aluno cooperativo (por outra dimensão), atento à detecção de problemas e criativo para a resolução dos mesmos, a formação se baseia no enquadramento deste aluno na sociedade atual. Que empresa não gostaria de um profissional com este perfil em seu quadro de "colaboradores"?

\subsection{OBRAS DIVERGENTES DAS ORIENTAÇÕES DAS POLÍTICAS PÚBLICAS DE FORMAÇÃO DE PROFESSORES}

As obras que divergem das orientações das políticas públicas para a formação de professores se apresentam em um número muito reduzido. Das vinte e quatro obras, apenas três delas compreendem a dança por um olhar crítico, 13\% das analisadas: Soares (1998), Bregolato (2000) e Marques (2007).

Soares (1998), em sua obra Improvisação \& Dança: Conteúdos para a Dança na Educação Física, busca quebrar certas hegemonias nas aulas de Educação Física e ultrapassar a dicotomia entre corpo e mente. Em relação à importância da dança na Educação Física, aponta:

Gestos e movimentos são expressão humana e esta é tudo aquilo que exceder o movimento meramente mecânico. E é esta transcendência do puramente biomecânico que nos faz humanos, capazes de observar, criar e desenvolver possibilidades de movimentos bastante diferenciados, contudo conscientes de uma gestualidade expressiva e significativa. (SOARES, 1998, p.16-17).

Segundo a autora, com a dança podemos resgatar e produzir cultura, que é o objeto da Educação. A dança possibilita a compreensão e a preservação das práticas culturais de movimentos dos povos, tendo em vista uma forma de autoafirmação de quem fomos e do que somos. Proporciona o encontro entre o homem e sua história, resgatando o sentido e atribuindo novos sentidos a sua vida. E complementa, afirmando que a dança na escola pode se apresentar como alternativa de transposição de certos limites impostos pelo mundo em que vivemos, como os do repasse e da cópia, na relação pedagógica, e os de ser massa de manobra nas relações sociais. 
Atos de Pesquisa em Educação - ISSN 1809-0354

Blumenau - vol. 11, n. 2, p.572-589 ago./nov. 2016

DOI: http://dx.doi.org/10.7867/1809-0354.2016v11n2p572-589

Bregolato (2000), apresentando a dança enquanto cultura corporal, aponta as três dimensões em que a mesma deveria se desenvolver na escola: das práticas dos movimentos corporais, da contextualização teórica, do princípio de valores e atitudes. A obra busca promover o desenvolvimento da Educação Física escolar numa perspectiva que compreenda o aluno como ser social ativo, com uma visão mais ampla e comprometida para o aluno que tem na escola a instituição legalmente responsável pela sua educação formal. Ao abordar a dança, Bregolato (2000) apresenta-a em seus mais variados estilos, buscando desenvolver as três dimensões apresentadas anteriormente, tendo por base uma concepção histórica crítico-social.

Finalizando as obras de posicionamento crítico, Marques (2007) busca elucidar o real compromisso social da dança na escola: ampliar a visão e as vivências corporais do aluno em sociedade a ponto de torná-lo um sujeito criador pensante de posse de uma linguagem artística transformadora. Tratando do assunto dança e classe social, a autora afirma que entender o porquê de algumas práticas estarem atreladas histórica e geograficamente a esta ou aquela classe social permite que compreendamos os processos sociais existentes relacionados às produções artísticas, a suas desigualdades e aos preconceitos em relação à dança.

É evidente o quanto essas obras se diferenciam significativamente das apontadas pelo posicionamento convergente. A dança aqui não se resume à formação da disciplina e à boa conduta, ao desenvolvimento dos elementos técnicos inerentes ao seu conhecimento. Amplia-se de modo a compreendê-la em outras dimensões, com outro compromisso social. Como cultura corporal historicamente produzida, a dança traz consigo uma série de relações que precisam ser tratadas na escola. Gênero, classe social, corporeidade: elementos apontados de forma crítica nas obras aqui expostas que denotam o trato com o seu conhecimento com outro significado. A mesma não se restringe ao auxílio na aprendizagem dos alunos em relação às suas habilidades básicas (escrita e leitura), tornando-se elemento de resgate e produção de cultura, conteúdo carregado de contradições socioculturais que precisam ser tematizados na escola.

\subsection{OBRAS QUE NÃO POSSUEM UM DIRECIONAMENTO EXPLÍCITO}


Atos de Pesquisa em Educação - ISSN 1809-0354

Blumenau - vol. 11, n. 2, p.572-589 ago./nov. 2016

DOI: $\underline{\text { http://dx.doi.org/10.7867/1809-0354.2016v11n2p572-589 }}$

As obras sem um direcionamento explícito compreendem $25 \%$, sendo seis das vinte e quatro analisadas. Definimos nesse quadro as obras que não deixaram explícito seu posicionamento em relação às orientações das políticas de formação de professores. Não têm claro o posicionamento dos autores em relação ao papel da educação e da dança enquanto conteúdo escolar. Artaxo e Monteiro (2008) e Camargo (1994) trazem informações referentes à teoria musical para uma melhor compreensão dos movimentos rítmicos corporais. Della (1983) e Brandão (1982) discutem o folclore enquanto manifestação popular de um povo, baseando-se em fatos históricos. Portinari (1995) e Mendes (1987) trazem o histórico da dança, apresentando sua evolução e os traços marcantes dessa cultura através dos tempos.

Após os quadros analisados e identificadas as obras em cada posicionamento, tomaremos como elemento de análise as sete disciplinas pesquisadas com base nas obras encontradas nos planos de ensino de cada uma delas. Compreendendo as disciplinas, podemos indicar possíveis direcionamentos da formação que cada curso e instituição buscam proporcionar aos seus acadêmicos.

\section{ANÁLISE DAS DISCIPLINAS A PARTIR DAS OBRAS REFERENCIADAS}

Para análise das disciplinas, tendo por base as obras anteriormente abordadas em cada um de seus planos de ensino, buscaremos compreender de que forma as disciplinas que tratam o conhecimento dança se posicionam quanto às orientações das políticas públicas de formação de professores e consequentemente a mesma postura em relação ao curso ao qual pertencem. Obviamente, estas análises são insuficientes para apontar o posicionamento político de cada instituição e curso superior. O que pretendemos é compreender se existe ou não alguma relação das políticas públicas de formação de professores com a formação que se pretende, acreditando que as referências bibliográficas básicas possam dar certo direcionamento ao nosso questionamento.

As disciplinas foram analisadas considerando suas obras e o posicionamento anteriormente indicado. Vale observar que para esta análise não estão sendo consideradas as obras que não apresentaram um posicionamento definido sobre as políticas públicas de formação docente, já que não apresentam influência considerável 
Atos de Pesquisa em Educação - ISSN 1809-0354

Blumenau - vol. 11, n. 2, p.572-589 ago./nov. 2016

DOI: http://dx.doi.org/10.7867/1809-0354.2016v11n2p572-589

sobre a análise. O diagrama a seguir demonstra o mecanismo utilizado para tal análise:

Figura 01 - Situação das disciplinas em relação às obras da bibliografia básica.

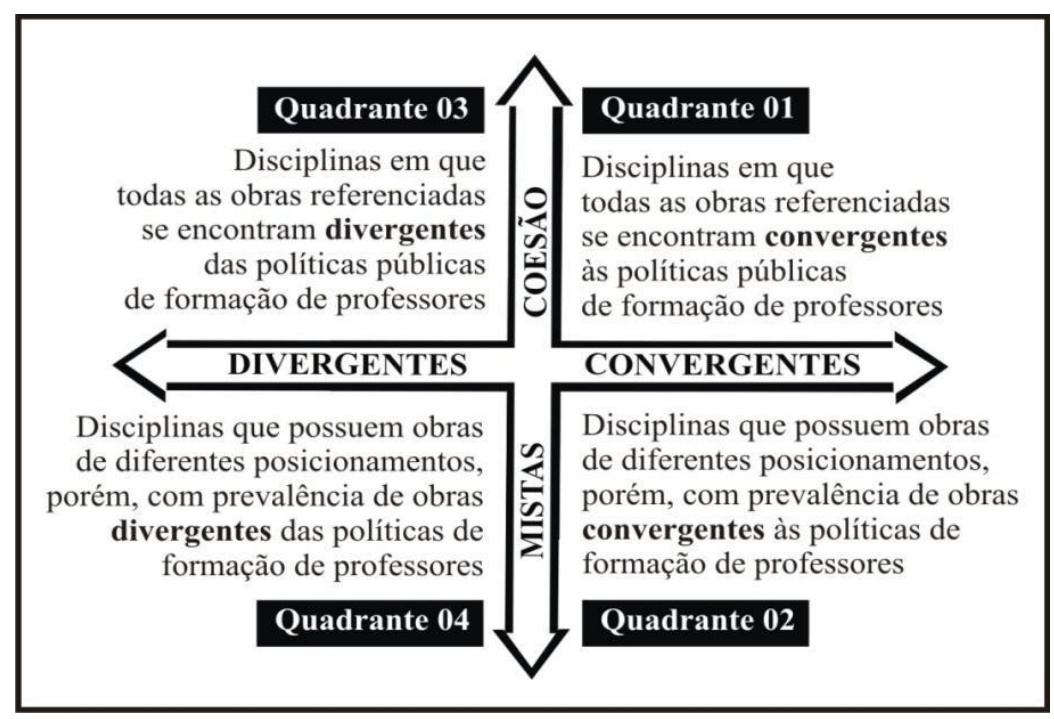

Fonte: Elaboração dos autores, 2014

Iniciamos a análise das sete disciplinas a partir do Quadrante 03: disciplinas que possuem todas as suas obras analisadas como divergentes das políticas de formação de professores, apresentando posicionamento crítico e conhecimento ampliado. Como previsto, nenhuma das sete disciplinas analisadas se enquadram nestas características, ou seja, nenhum dos cursos de licenciatura em Educação Física da região sul catarinense tratam o conteúdo dança tendo por referência uma bibliografia inteiramente crítica, partindo de um conhecimento contextualizado historicamente, tratado tecnicamente e discutido sócio culturalmente.

Contrariamente a este quadrante se encontram as disciplinas contempladas no Quadrante 01: disciplinas em que todas as obras referenciadas se encontram convergentes às políticas públicas de formação de professores, consideradas nesta pesquisa de posicionamento não crítico, com base num conhecimento estritamente técnico, prático e instrumental. Neste quadrante se apresentam a maior parte das disciplinas, somando três ao total: Teoria e Metodologia da Dança e das Atividades Rítmicas (IES IV); Dança, Ritmo e Movimento (IES II) e Dança na Escola (IES III). Cada uma das disciplinas possui três obras como referência básica. A IES IV e a IES II possuem apenas estas disciplinas que tratam do conhecimento dança na 
Atos de Pesquisa em Educação - ISSN 1809-0354

Blumenau - vol. 11, n. 2, p.572-589 ago./nov. 2016

DOI: http://dx.doi.org/10.7867/1809-0354.2016v11n2p572-589

graduação, portanto nos apresentam traços fortes de um posicionamento não crítico em relação ao conteúdo dança, apresentando forte relação com as orientações das políticas públicas de formação docente através do desenvolvimento das competências.

No Quadrante 02 encontram-se as disciplinas que possuem obras de diferentes posicionamentos, porém com prevalência de obras convergentes às políticas de formação de professores. São elas: Formação Rítmica do Movimento e Dança (IES V) e Metodologia da Dança e das Atividades Rítmicas II (IES I). Nesta análise, vale ressaltar o número considerável de obras citadas como referência básica na disciplina Formação Rítmica do Movimento e Dança da IES V. Foram dez obras analisadas, sendo apenas uma de posicionamento crítico e o predomínio de oito obras posicionadas de forma não crítica (posicionamento não explícito em uma delas). Torna-se inevitável que esta disciplina tenha um caráter fortemente acrítico por este motivo. O número de obras que convergem com as políticas públicas é notadamente superior e relevante a esta análise. A disciplina Metodologia da Dança e das Atividades Rítmicas II (IES I) apresenta cinco obras, sendo duas de posicionamento não crítico e uma de posicionamento crítico (duas sem posicionamento explícito) apresentando certo equilíbrio entre as obras.

Para análise do Quadrante 04, algumas considerações precisam ser feitas. As disciplinas Metodologia da Dança e das Atividades Rítmicas I (IES I) e Atividades Rítmicas e Expressivas (IES III) apresentam o mesmo número de obras de posicionamento crítico e não crítico. Porém, analisando o pequeno número de livros apresentados que possuem um posicionamento crítico (três obras das vinte e quatro analisadas), acreditamos que as disciplinas oferecem ampla possibilidade de debate dos direcionamentos das políticas públicas, o que por si só pode ser considerado como uma postura crítica. Destaque para a disciplina Metodologia da Dança e das Atividades Rítmicas I da IES I, que apresenta o maior número de obras críticas em uma única disciplina. Entre as analisadas, estas duas disciplinas são as que mais divergem das orientações das políticas públicas, sendo que suas obras tratam da dança de maneira mais ampliada, apresentando outras possibilidades de trato com o conteúdo dança para os acadêmicos em relação à Educação Física escolar. 
Atos de Pesquisa em Educação - ISSN 1809-0354

Blumenau - vol. 11, n. 2, p.572-589 ago./nov. 2016

DOI: http://dx.doi.org/10.7867/1809-0354.2016v11n2p572-589

Observando as disciplinas em sua totalidade, destacamos a obra de Nanni (2002) presente em cinco das sete analisadas, demonstrando certo prestígio e consolidação na área da dança. A obra foi considerada como convergente às orientações políticas em um posicionamento não crítico.

A grande maioria das disciplinas se encontra convergente com as orientações das políticas públicas de formação de professores: em cinco delas prevaleceram os preceitos da formação para a empregabilidade e em outras duas as obras de posicionamento crítico dividem o mesmo espaço com as obras acríticas.

\section{CONCLUSÃo}

Torna-se evidente a relação existente entre as políticas de formação de professores e as formações oferecidas pelas instituições de ensino superior da região sul catarinense. Infelizmente, o que se apontava logo após as reformas educacionais no início da década de 1990 apresentam ainda hoje fortes indícios na formação de professores de Educação Física nas instituições pesquisadas. Todas as disciplinas, de todos os cursos, apresentaram obras de posicionamento conservador tornando evidente a estreita relação presente entre políticas públicas e formação de professores.

Seguindo as orientações destas políticas, o conteúdo dança tende a se reduzir ao gesto técnico e suas questões práticas. Mesmo que a relação com o mercado de trabalho não seja tão evidente e direta, marcas de um "saber fazer" se apresentam e o que se busca com a dança acaba sendo o mesmo que se busca com outros conteúdos da cultura corporal. Constituem-se padrões de ensino que juntamente com o repasse de valores e atitudes morais, acabam por formar o aluno para o mercado de força de trabalho, sem que ao menos o mesmo compreenda o que é esse mercado e o valor que possuirá estando inserido nele.

Nossa busca, a partir de então, volta-se a compreensão da dança numa perspectiva que supere seu trato a partir de suas caraterísticas práticas e instrumentais, compreendendo as possibilidades de desenvolvimento psíquico, atreladas a apropriação teórica deste objeto nas aulas de Educação Física.

\section{VILDACIR ORTIGARA}


Atos de Pesquisa em Educação - ISSN 1809-0354

Blumenau - vol. 11, n. 2, p.572-589 ago./nov. 2016

DOI: http://dx.doi.org/10.7867/1809-0354.2016v11n2p572-589

Doutor em Educação pela Universidade Federal de Santa Catarina - UFSC (2002), bolsa doutorado sanduíche na Università Degli Studi di Urbino-Itália. É professor da Universidade do Extremo Sul Catarinense (UNESC), atuando nos Cursos de Graduação em Educação Física e no Programa de Pós-Graduação em Educação, do qual é o Coordenador, período 2014-2016.

\section{BRUNA CAROLINI DE BONA}

Mestre em Educação pela Universidade do Extremo Sul Catarinense - UNESC (2013). Professora no curso de Educação Física na mesma instituição.

\section{ANA LÚCIA CARDOSO}

Mestre em Educação Física pela Universidade Federal de Santa Catarina - UFSC (2003) na área de teoria prática pedagógica em Educação Física. Atualmente é professora do curso de Licenciatura em Educação Física e Pedagogia da Universidade do Extremo Sul Catarinense (UNESC)

\section{CARLOS AUGUSTO EUZÉBIO}

Doutorando do Programa de Pós-Graduação em Educação da Universidade Federal de Santa Catarina - UFSC na linha trabalho e educação. Docente na Universidade do Extremo Sul Catarinense - UNESC.

\section{REFERÊNCIAS}

ARTAXO, Inês; MONTEIRO, Gizele de A. Ritmo e movimento. Teoria e Prática. São Paulo: Phorte, 2008.

BRASIL. Conselho Nacional de Educação. Resolução CNE/CP 01. Diário Oficial da União. Brasília, 18 fev. 2002a.

. Conselho Nacional de Educação. Resolução CNE/CP 02. Diário Oficial da União. Brasília, 19 fev. 2002b.

. Conselho Nacional de Educação. Resolução CNE/CES 07/2004, 31 de março de 2004.

. Ministério da Educação. Lei de Diretrizes e Bases da Educação Nacional. LDB 9.394, de 20 de dezembro de 1996.

Ministério da Educação e do Desporto. Parâmetros Curriculares Nacionais. vol. 7. Brasília: 1997.

BRANDÃO, Carlos R. O que é Folclore. São Paulo. Brasiliense, 1982.

BREGOLATO, Roseli A. Cultura Corporal da Dança. São Paulo: Ícone, 2000.

BRIKMAN, Lola. A linguagem do movimento corporal. São Paulo: Summus, 1989. 
Atos de Pesquisa em Educação - ISSN 1809-0354

Blumenau - vol. 11, n. 2, p.572-589 ago./nov. 2016

DOI: http://dx.doi.org/10.7867/1809-0354.2016v11n2p572-589

CALAZANS, Maria Julieta Costa; CASTILHO, Jacyan; GOMES, Simone (Coord.) Dança e educação em movimento. São Paulo: Cortez, 2003.

CAMARGO, Maria L. M. Música/movimento: um universo em duas dimensões. Aspectos técnicos e pedagógicos na Educação Física. Belo Horizonte: Villa Rica, 1994.

CEPAL/UNESCO. Educación y conocimiento: eje de la transformación productiva com equidad. Santiago, 1992.

DANTAS, Estélio H. M. Alongamento e Flexionamento. 5 ed. Rio de Janeiro: Sharpe, 2005.

DAVID, Nivaldo A. N. A formação de professores de educação básica: dilemas atuais para a educação física. Revista Brasileira de Ciências do Esporte, Campinas, v. 23, n. 2, p. 119-133, jan. 2002.

DELLA, Mônica L. Manual do Folclore. 2 ed. São Paulo: Edart, 1983.

EUZÉBIO, Carlos A.; ORTIGARA, Vidalcir. Na teoria a prática é outra? Análise do conhecimento esporte nos cursos de formação inicial de professores de Educação Física no sul catarinense. Revista Brasileira de Ciências do Esporte, Florianópolis, v.33, n. 1, p. 653 a 669, 2011.

EVANGELISTA, Olinda; SHIROMA, Eneida O. Um fantasma ronda o professor: a mística da competência. In: MORAES, Maria Célia M. (Org). Iluminismo às Avessas: produção do conhecimento e políticas de formação docente. Rio de Janeiro: DP\&A, 2003.

FERREIRA, Vanja. Dança escolar: um novo ritmo para a educação física. Rio de Janeiro: Sprint, 2009.

GENTILI, Pablo. Neoliberalismo e educação: manual do usuário. In. DA SILVA, Tomaz Tadeu; GENTILI, Pablo (Orgs.). Escola S. A.: quem ganha e quem perde no mercado educacional do neoliberalismo. Brasília: CNTE, 1996.

GARCIA, Ângel; HAAS, Aline N. Ritmo e Dança. Canoas: ULBRA, 2003.

HASELBACH, Barbara. Dança, improvisação e movimento: expressão corporal na educação física. Rio de Janeiro: Ao Livro Técnico, 1988.

MARQUES, Isabel A. Dançando na escola. 4 ed. São Paulo: Cortez, 2007.

MENDES, Miriam G. A dança. São Paulo: Ática, 1987.

MORAES, Maria C. M. Recuo da Teoria. In: MORAES, Maria Célia M. (Org). Iluminismo às Avessas: produção do conhecimento e políticas de formação docente. Rio de Janeiro: DP\&A, 2003. 
Atos de Pesquisa em Educação - ISSN 1809-0354

Blumenau - vol. 11, n. 2, p.572-589 ago./nov. 2016

DOI: http://dx.doi.org/10.7867/1809-0354.2016v11n2p572-589

MORAES, Maria C. M. Indagações sobre o conhecimento no campo da educação. Revista Perspectiva, Florianópolis, v.27, n.2, p. 315-346, 2009.

MORAES, Maria C. M.; TORRIGLIA, Patrícia L. Sentidos de ser docente e da construção de seu conhecimento In: MORAES, Maria Célia M. (Org.). Iluminismo às Avessas: produção do conhecimento e políticas de formação docente. Rio de Janeiro: DP\&A, 2003.

NANNI, Dionísia. Dança educação: princípios, métodos e técnicas. 4 ed. Rio de Janeiro: Sprint. 2002.

OSSONA, Paulina. A educação pela dança. São Paulo: Summus, 1988.

PORTINARI, Maribel B. História da dança.2 ed. Rio de Janeiro: Nova Fronteira, 1995.

PRINA, Federica C.; PADOVAN, Maurizio. A dança no ensino obrigatório. Lisboa: Fundação Calouste Gulbenkian, 2000.

RANGEL, Nilda B. C. Dança, educação, educação física: propostas de ensino da dança e o universo da educação física. Jundiaí: Fontoura, 2002.

SOARES, Andresa S. Improvisação e dança: conteúdos para a dança na educação física. Florianópolis: UFSC, 1998.

TAFFAREL, Celi N. Z. Formação de professores de Educação Física: Diretrizes para a Formação Unificada. Revista Kinesis, Santa Maria, v.30, n.1, p. 95-113, 2012.

VERDERI, Érica B. L. P. Dança na Escola. Rio de Janeiro: Sprint, 1998.

Artigo recebido em junho de 2016.

Aprovado em junho de 2016

Este trabalho está licenciado com uma Licença Creative Commons - Atribuição 4.0 Internacional 